\title{
Analisis Data Penelitian Menggunakan Perangkat Lunak Excel
}

\author{
Rusli $^{\text {a }}$, Suradi ${ }^{\mathrm{a}}$, Abdul Rahman ${ }^{\mathrm{a}}$, Said Fachry Assagaf a , Hastuty ${ }^{\mathrm{b}, *}$ \\ ${ }^{a}$ Universitas Negeri Makassar, Indonesia. \\ ${ }^{b}$ Universitas Muhammadiyah Parepare, Indonesia.
}

\begin{abstract}
Data analysis is an absolute step in quantitative research, the teacher's lack of understanding in conducting data analysis has an impact on the teacher's lack of enthusiasm in conducting research and writing scientific articles. This data analysis training uses excel software. Partners of the Community Partnership Program (PKM) are mathematics teachers who join the Bantaeng district MGMP. This training is carried out offline at SMPN 3 Bantaeng Regency. This training aims to help teachers to be skilled in statistical data processing, understand the steps in conducting research with quantitative data. Passion for writing scientific articles for publication in journals. Through this training, it is hoped that these teachers will be able to process raw research data using excel software and interpret the output. This training is held in the form of material presentation, hands-on practice with excel software, and 'task work'. The results achieved are 1) Teachers are skilled at processing research data using excel software, 2). Teachers better understand the steps in conducting research, 3). Able to write scientific articles properly and correctly.
\end{abstract}

\section{Pendahuluan}

Kegiatan penelitian baik itu dilakukan melalui pendekatan kuantitatif maupun kualititatif tidak akan terlepas dari data, pengolahan data, dan analisinya. Data merupakan bahan baku informasi untuk memberikan gambaran spesifik tentang obyek penelitian yang kita teliti. Data adalah fakta empirik yang dikumpulkan oleh peneliti guna memecahkan masalah atau menjawab pertanyaan penelitian. (Aedi, 2010).

Dalam rangka pengembangan profesional, guru tidak bisa melepaskan dirinya dari kegiatan penelitian. Penelitian yang terkait langsung dengan tugas pokok dan fungsinya serta berdampak langsung terhadap peningkatan kualitas pembelajaran. Dalam kegiatan penelitian ini, guru memiliki peran strategis dalam pengembangan kompetensi profesional sekaligus sebagai upaya dalam meningkatkan dan memperbaiki proses maupun hasil belajar siswa. (Setiawan, 2008)

Kemampuan menulis karya tulis ilmiah bagi seorang guru merupakan kompetensi utama selain mengajar yang mutlak dimiliki, karena tuntutan adanya kredit dari karya tulis lmiah untuk kenaikan pangkat dan jabatan guru. Kemampuan dan kepekaan guru melihat keadaan siswa dan sekitarnya perlu dilatih dan diasah terus menerus agar menjadi suatu pembiasaan positif dan menjadikan pengalaman yang baik dalam berkarya, terutama dalam meneliti dan menuliskan temuannya dengan baik dan benar, dengan demikain pemahaman guru terhadap keadaan sekitarnya menjadi baik. Kompetensi lainnya adalah guru dituntut pula agar mampu mendesiminasikan hasil penelitiannya dalam pengajarannya. Kemampuan memahami data dan analisis statistika serta keterampilan menggunakan perangkat lunak statistik diharapkan mampu meningkat- kan motivasi guru melakukan penelitian. (Rusli, Rahman, Ahmar, Sahid, \& Hastuty, 2019).

Perangkat lunak excel dipilih sebagai alternatif dalam pengolahan data penelitian, karena aplikasi ini sangat familiar pada masyarakat khussnya oleh guru-guru. Guru-guru Sulawesi Selatan pada umumnya menggunakan perangkat lunak microsoft office sebagai alat bantu dalam menyelesaikan tugas-tugasnya sebagai guru. Microsoft Excel adalah sebuah program aplikasi lembar kerja spreadsheet yang dibuat dan didistribusi-kan oleh Microsoft Corporation untuk sistem operasi Microsoft Windows dan Mac OS. Software ini dikenal juga sebagai Microsoft Office Excel, MS. Excel atau sering disebut sebagai Excel saja. Oleh sebab itu syarat utama untuk bisa menggunakan program aplikasi excel ini,

\footnotetext{
* Corresponding author:

E-mail address: rusli.siman@unm.ac.id (Rusli)
} 
komputer yang anda gunakan harus sudah terinstal sistem operasi (operating sistem) Windows atau Mac terlebih dahulu. Microsoft Excel adalah salah satu dari sekian banyak Program Aplikasi yang terdapat dalam paket Microsoft Office. (Rusli, Rahman, Upu, Ahmar, \& Hastuty, 2020).

Microsoft excel merupakan salah satu aplikasi yang termasuk dalam paket mikrosoft office bersama dengan microsoft word, powerpoint dan lainnya dengan demikian boleh dikatakan bahwa setiap guru yang memiliki komputer baik itu komputer destop, laptop maupun notebook pada umumnya dalam perangkat komputer yang dimilikinya tersebut telah terinstal microsoft excel sebagai bagian dari microsoft office. Fasilitas analisis statistika yang dimiliki oleh excel terdapat dalam paket addons, paket ini tidak secara otomatis aktif dan langsung digunakan sebagaimana dengan fiturfitur lainnya, namun untuk mengaktifkan juga sangat mudah.

Berdasarkan uraian di atas, dipandang perlu melakukan kegiatan pelatihan pengolahan data penelitian menggunakan perangkat lunak komputer untuk para guru, dalam kegiatan pelatihan ini digunakan perangkat lunak Microsoft excel. dikhususkan bagi guru-guru matematika Sekolah Menegah Pertama yang bergabung dalam MGMP SMP kabupaten Bantaeng. Tujuan yang hendak dicapai dalam pelatihan ini adalah: 1) membantu para guru-guru untuk terampil melakukan pengolahan data statistik, 2) memahami langkah-langkah dalam melakukan penelitian dengan data kuantitatif dan 3) meningkatnya emangat guru-guru dalam menulis artikel ilmiah untuk dipublikasi pada jurnal.. Harapannya, setelah pelatihan guru-guru tersebut mampu mengolah data mentah hasil penelitian menggunakan software excel serta melakukan interpretasi terhadap luarannya.

\section{Metode Pelaksanaan}

Permasalahan yang dihadapi oleh mitra dalam hal ini guru-guru Matematika SMP kabupaten Bantaeng yang bergabung dalam kelompok MGMP, sebagaimana diutarakan di atas, akan diselesaikan dalam bentuk pelatihan, kegiatan ini dilakukan dalam dalam bentuk 1) penyajian materi, 2) praktikum terbimbing, dan 3) presentasi.

Pada tahap penyajian materi, peserta diberi materi-materi mengenai konsep penelitian kuantitatif, konsep pengolahan data, Teknik pengujian hipotesis statistik, dan jenis- jenis statistik uji yang cocok digunakan sesuai dengan karakteristik data penelitian.

Pada tahap praktikum terbimbing, di awali dengan pembimbingan cara mengaktifkan paket toolspack analysis excel, selanjutnya dilakukan praktikum dan pembimbingan untuk statistik deskriptif dan statistik inferensial.

Selanjutnya pada tahap presentasi, peserta melakukan presentasi dan diskusi tentang apa yang telah dikembangkan dalam kerja mandiri setelah dilakukan praktikum terbimbing.

Kegiatan pelatihan ini dilaksanakan di SMP Negeri 3 Bantaeng kabupaten Bantaeng, dengan melibatkan peserta sebanyak 22 orang. Kegiatan ini di buka oleh bapak Kepala Dinas Pendidikan dan Kebudayaan Kabupaten Bantaeng, dan pada sambutannya beliau sangat mengapresiasi kegiatan ini sebagai wadah menguprade kompetensi guru matematika dalam lingkup dinas Pendidikan dan kebudayaan kabipaten Bantaeng.

\section{Hasil dan Pembahasan}

Penggunaan fitur statistika di excel digunakan secara maksimal bila Analysis Toolpak di aktifkan. Analysis Toolpak merupakan sebuah add-ins yang tersedia pada microsoft excel mulai versi 2007 sampai versi 365 sekarang ini. Dalam Analysis Toolpak terdapat beberapa fasilitas untuk menganalisis data seperti Anova: Single Factor, Anova: Two Factor With Replication, Anova: Two Factor Withot Replication, Correlation, Covariance, Descriptive Statistics (Warner \& Meehan, 2001). Untuk mengaktifkan Add-Ins Analysis Toolpak di Excel langkah pertama Klik tombol Office, lalu Pilih Excel Options, Pada window Excel Options pilih Add Ins Pada bagian Manage pilih Excel Add Ins, kemudian klik Go, Akan muncul kotak dialog Add Ins Centang Analysis ToolPack lalu Klik OK. Jika muncul pesan "Microsoft Office Excel can't run tthis add in, This feature is not currently installed. Would you like to install it now? Klik Yes. Akan muncul window configuration progress tunggu hingga proses instal add-ins selesai. Jika berhasil menginstal Add-in terebut, maka di exel akan muncul ribbon menu baru, yaitu Data Analysis. Tampilan fitur yang terdapat dalam Data Analysis bisa dilihat pada gambar 1.

Hasil dari aktifnya analysis toolspack excel, dapat dilihat pada gambar 2, yang berisi tentang statistik uji baik statistik deskriptif maupun statistik inferensial. 
Hasil dari kegiatan pelatihan ini guru-guru matematika SMP sekabupaten Bantaeng sebagai peserta, telah mampu dan terampil melakukan analisis data secara deskriptif, membuat tabel distribusi frekuensi, juga terampil dlam melakukan uji komparasi diantaranya adalah uji t sampel berpasangan, uji $t$ sampel independen, anavar satu jalur maupun dua jalur, demikian juga untuk menguji analisis korelasional, meliputi uji korelasi, uji regresi linear sederhana, maupun regresi linear ganda. Kemampuan guru tersebut kami sajikan hanya beberapa sebagai contoh kemampuan yang telah dimiliki, kemampuan tersebut diantaranya adalah kemampuan dalam membuat ringkasan data. Untuk melakukan ringkasan data dilakukan pada menu statistika deskriptif excel pada Gambar 3 ..

\section{Pada Office 2007: silk tanda windows di layar kiri. Pada Office 2010-}

\section{3 kalik menu file}

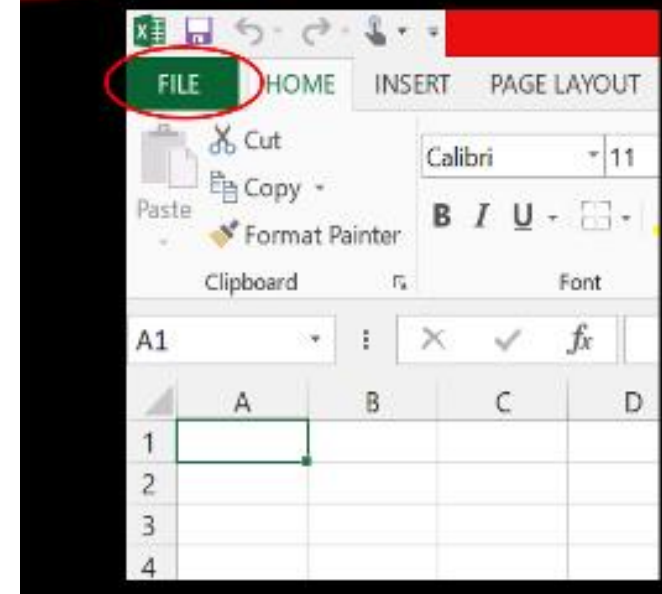

\section{Kemudian anda Klik Options}

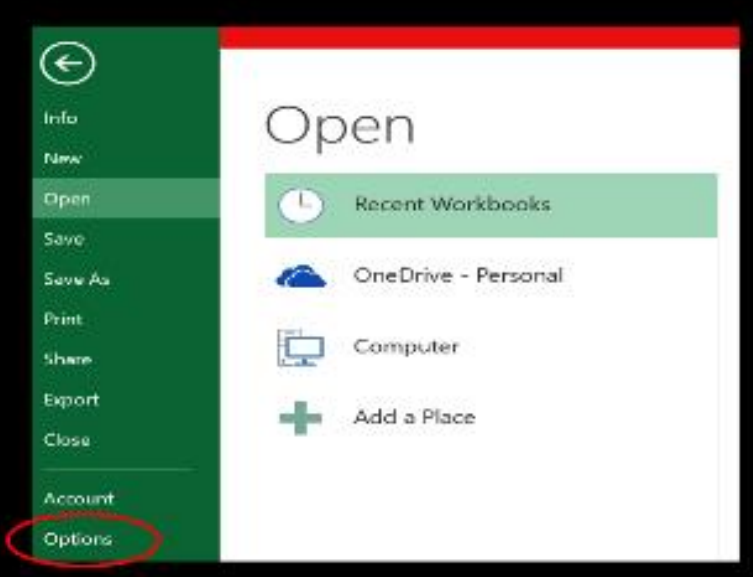

Gambar 1: Fitur mengaktifkan Menu Data Analysis pada Toolspack Excel

\begin{tabular}{|l|l|}
\hline Data Analysis & \\
\hline Analysis Tools & OK \\
\hline \begin{tabular}{l|l|}
\hline Anova: Single Factor \\
Anova: Two-Factor With Replication \\
Anova: Two-Factor Without Replication \\
Correlation \\
Covariance \\
Descriptive Statistics \\
Exponential Smoothing \\
F-Test Two-Sample for Variances \\
Fourier Analysis \\
Histogram
\end{tabular} \\
\hline
\end{tabular}

Gambar 2. Fitur Data Analysis di Excel 


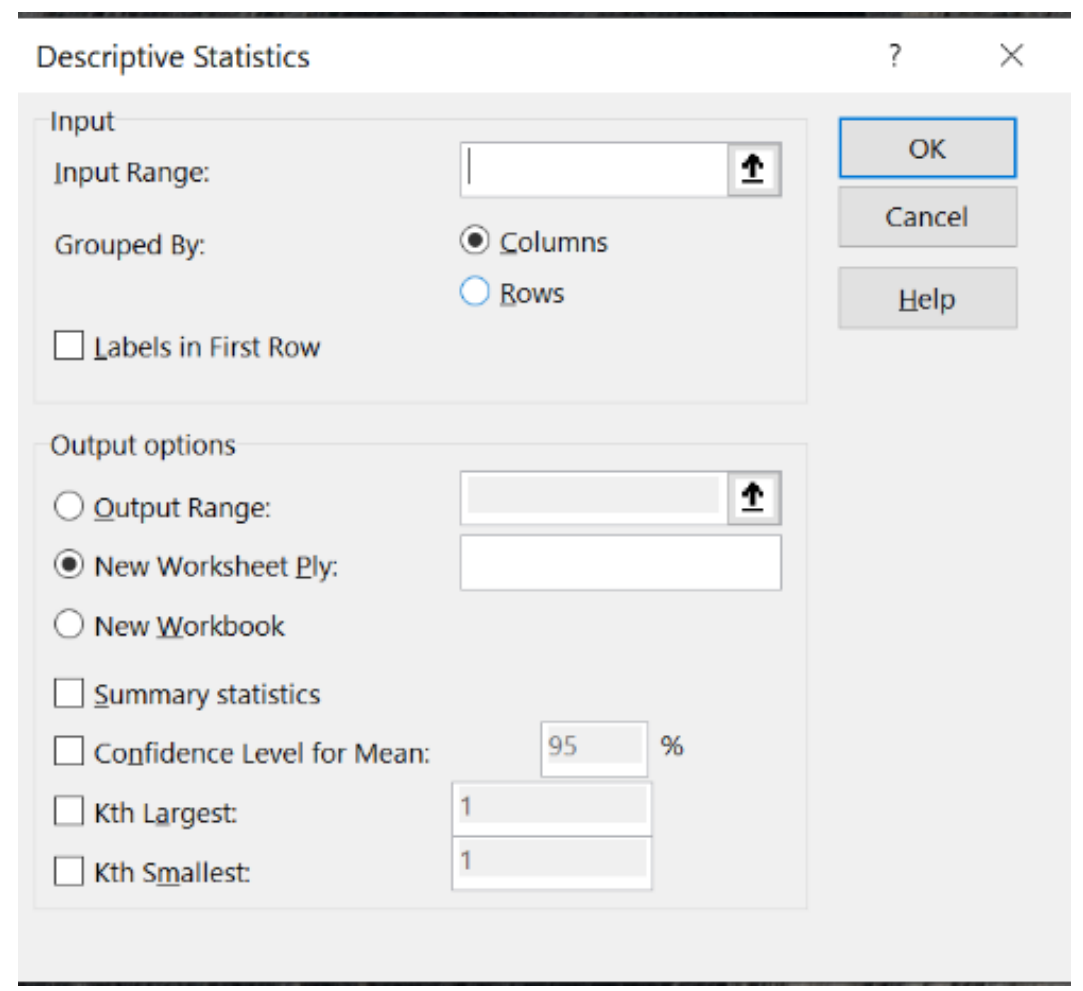

Gambar 3. Menu Statistik Deskriftif di Excel

Dilihat dari Karakteristik tempat mengajar peserta PKM ini, yang dibagi dalam cluster daerah Pedesaan, Pinggiran Kota, dan daerah perkotaan dapat dilihat pada gambar 4.

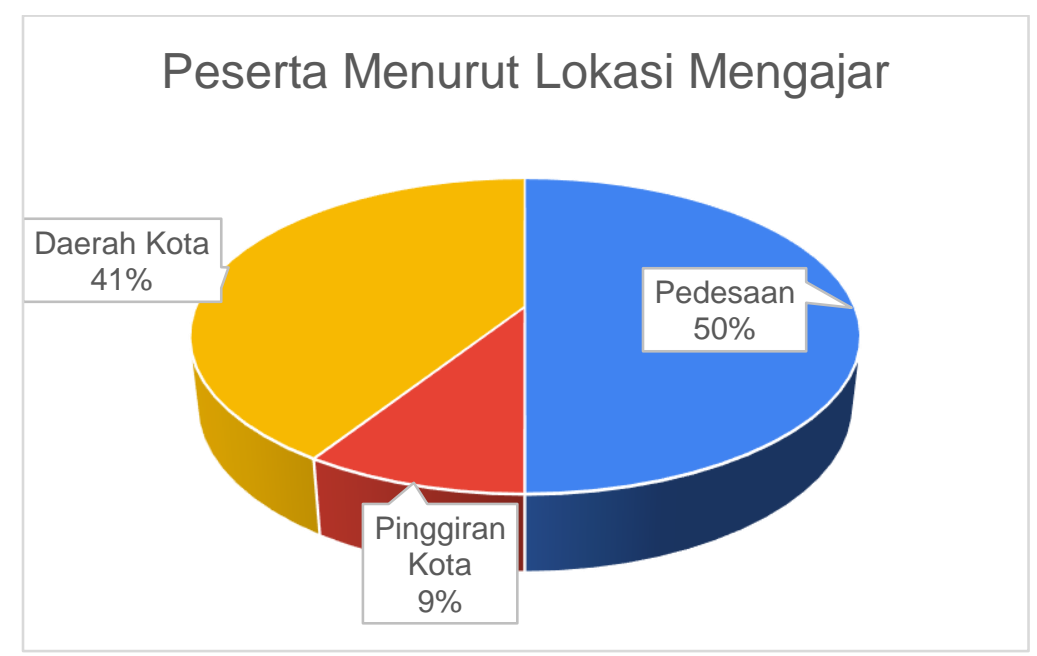

Gambar 4. Peserta Pelatihan Menurut Lokasi Sekolah Tempat Mengajar

Sedangkan bila dilihat dari Karakteristik status sekolah tempat mengajar peserta PKM ini, yang dibagi dalam cluster sekolah negeri dan sekolah swasta dapat dilihat pada gambar 5. 


\section{Peserta Pelatihan Menurut \\ Status Sekolah}

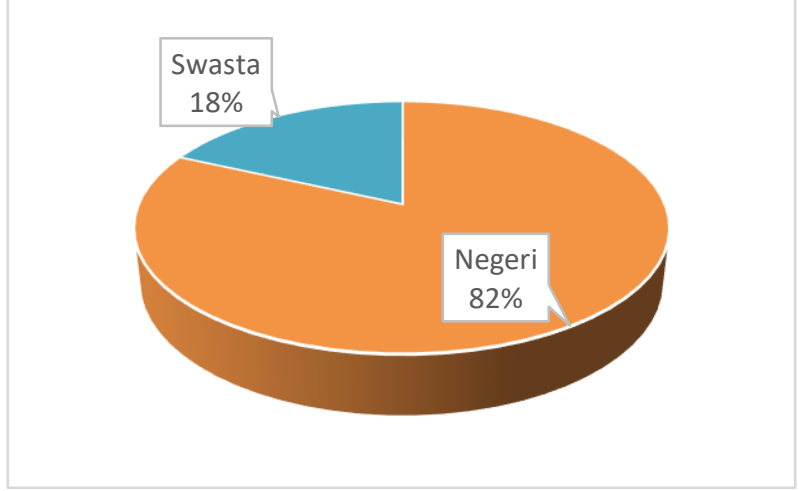

Gambar 5. Peserta Pelatihan Menurut Status Sekolah Tempat Mengajar

Karakteristik peserta pelatihan ini menurut jenjang pendidikan dapat dilihat pada gambar 6. Hasil analisis dari angket sikap menggunakan skala liker skala 1 - 5 kepada peserta PKM yang mempertanyakan sikap mereka terhadap pengolahan data penelitian dengan menggunakan perangkat lunak excel dapat dilihat pada table 1.

Tabel 1. Sikap Peserta PKM terhadap aplikasi pengolahan data Microsoft Excel

\begin{tabular}{|c|c|c|}
\hline Sikap & Indikator & Rata-Rata \\
\hline \multirow{5}{*}{$\begin{array}{c}\text { Sikap Perserta PKM terhadap } \\
\text { aplikasi pengolahan data Microsoft } \\
\text { Excel }\end{array}$} & $\begin{array}{l}\text { Menunjukkan ketertarikan pada cara analisis data } \\
\text { menggunakan excel }\end{array}$ & 4,73 \\
\hline & $\begin{array}{l}\text { Menunjukkan kesungguhan ketika menggunakan microsoft } \\
\text { excel dalam pengolahan data penelitian }\end{array}$ & 4,45 \\
\hline & Mengetahui kegunaan Microsoft Excel & 4,36 \\
\hline & $\begin{array}{l}\text { Usaha dalam mencari Referensi mata pelajaran matematika } \\
\text { pada web site }\end{array}$ & 3,91 \\
\hline & Menunjukkan ketertarikan pada fasilitas microsoft excel & 4,27 \\
\hline
\end{tabular}

Hasil dari angket sikap dengan menggunakan skala likert menghasilkan sikap yang positif dengan rata-rata skor keseluruhan adalah 4,35, lebih dari rata-rata skor netral 3. Indikator menunjukkan ketertarikan pada cara analisis data menggunakan microsoft excel memperoleh rata-rata skor paling tinggi yaitu 4,73. Sedangkan indikator usaha dalam mencari referensi pelajaran matematika di website memperoleh rata-rata skor terendah yaitu 3,91.

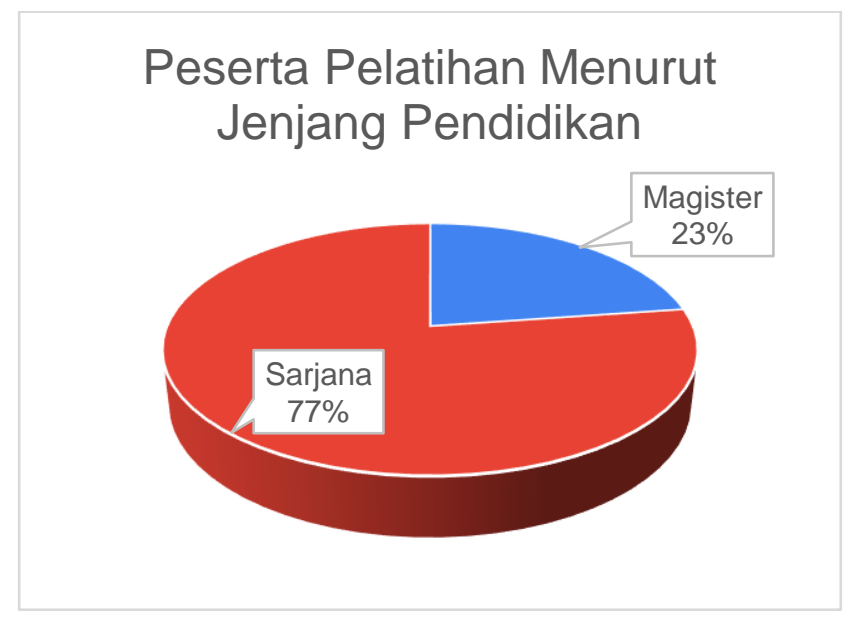

Gambar 6. Peserta Pelatihan Menurut Jenjang Pendidikan 


\section{Kesimpulan}

Kegiatan PKM yang dilaksanakan di SMPN3 Bantaeng Kabupaten Bantaeng dengan menyajikan materi analisis data penelitian perangkat lunak excel bagi guru guru sekolah menengah pertama di kabupaten Bantaeng mendapatkan respons yang positif terbukti dengan semangatnya mereka mengikuti pelatihan. Skor indikator sikap terhadap penggunaan excel dalam pengolahan data rata-rata keseluruhan sebesar 4,35, skor ini berada di atas skor netral 3 .

Pelatihan ini memberikan hasil bahwa guru-guru mampu menggunakan perangkat lunak excel atau paket statistika yang dimiliki oleh excel dalam menagnalisis data penelitian atau sejenisnya. Statistik uji yang mampu digunakan oleh guru-guru diantaranya Anova: Single Factor, Anova: Two Factor With Replication, Anova: Two Factor Withot Replication, Correlation, Covariance, Descriptive Statistics,, F-Test Two-Sample for Variances, Fourier Analysis, Histogram, Regression, Sampling, t-Test : Paired Two Sample for Means, t-Test : Two Sample Asumming Equal Variances, t-Test : Two Sample Asumming Unequal Variances.

\section{Acknowledgements}

Penulis mengucapkan terima kasih kepada Universitas Negeri Makassar dan kepada Fakultas Matematika dan Ilmu Pengetahuan Alam, serta jurusan Matematika Universitas Negeri Makassar, yang telah memberikan dana PNBP Tahun 2021 untuk pelaksanaan kegiatan ini.

\section{References}

Aedi, N. (2010). Pengolahan dan Analisis Data Hasil Penelitian. Bandung: Fakultas Ilmu Pendidikan - UPI.

Rusli, R., Rahman, A., Ahmar, A. S., Sahid, S., \& Hastuty, H. (2019). Pengolahan data menggunakan Toolspack Analysis Excel pada guru-guru di Kabupaten Takalar. Proseding Seminar Nasional Lembaga Penelitian UNM Makassar, 193-196.

Rusli, R., Rahman, A., Upu, H., Ahmar, A. S., \& Hastuty, H. (2020). The Use of Excel Statistics for Research Data Processing for Teachers of SMAN 3 Barru, Barru Regency. Mattawang: Jurnal Pengabdian Masyarakat, Vol. 1 No. 1, https://doi.org/10.35877/454RI.mattawang168, 8-12.

Setiawan, I. G. (2008). Penerapan pengajaran kontekstual berbasis masalah untuk meningkatkan hasil belajar biologi siswa kelas x2 sma laboratorium singaraja. Jurnal Penelitian dan Pengembangan Pendidikan, 42 - 59.

Warner, C. B., \& Meehan, A. M. (2001). Microsoft Excel ${ }^{\mathrm{TM}}$ as a tool for teaching basic statistics. Teaching of Psychology, 28(4), 295-298. doi:https://doi.org/10.1207\%2FS15328023TOP2804_11 